\title{
Quality assessment of the practice of focused antenatal care (FANC) in rural and urban primary health centres in Ekiti State
}

\author{
Ikeoluwapo O. Ajayi ${ }^{1}$, Damilola C. Osakinle ${ }^{1}$, Eunice O. Osakinle ${ }^{2}$ \\ ${ }^{1}$ Department of Epidemiology and Medical statistics, University of Ibadan, Ibadan, Nigeria \\ ${ }^{2}$ Department of Guidance and Counseling, Faculty of Education, Ekiti State University, Ado Ekiti, Nigeria \\ Email: dammielolie@yahoo.com
}

Received 25 December 2012; revised 30 January 2013; accepted 8 February 2013

Copyright (c) 2013 Ikeoluwapo O. Ajayi et al. This is an open access article distributed under the Creative Commons Attribution License, which permits unrestricted use, distribution, and reproduction in any medium, provided the original work is properly cited.

\section{ABSTRACT}

Objective: To ascertain that standard antenatal care (Focused antenatal care) is being received at the Primary Health Care level in urban and rural areas of Ekiti State and to determine the facilitating factors and challenges to the practice of FANC in urban and rural areas. Design: Cross sectional. Setting: Primary Health Centers Participants: Pregnant women and Heads of health facilities. Methods: Two hundred respondents each from urban and rural areas primary health centres were proportionately selected from 18 primary health centers using simple random sampling. Exit interviews were conducted using the antenatal care exit interview form of the Safe Motherhood Needs Assessment package. In-depth Interviews were conducted with the heads of selected facilities. Data was analysed using descriptive statistics and Chi square test and content analysis for indepth interview. Results: More respondents 58 (29.3\%) from the urban areas had the minimum contents compared to $41(20.7 \%)$ of the rural respondents $(p<$ $0.05)$ and $178(90.8 \%)$ of the urban were taught a range of health education topics compared to 177 $(88.5 \%)(p=0.45)$. Urban respondents were about 1.6 times more likely to receive the minimum contents than rural respondents. In-depth interview results explicated the facilitating factors and challenges to focused antenatal care in the study areas. Conclusion: The findings of this study is consistent with other studies establishing the fact that better health service is available to urban residents than rural residents; however, this study has succeeded in comparing the documented standard of antenatal care with what was being practiced in the selected PHCs of the state. The basic contents of focused antenatal care in Ekiti state were received by a small proportion of the respondents, suggesting that focused antenatal care had not fully translated into quality service; one major challenge to the delivery of standard antenatal care was inadequate number of skilled health workers especially in the rural areas. The gap between quality and utilisation of antenatal in urban and rural areas is gradually being closed up; this success should be improved upon and maintained.

Keywords: Focused Antenatal Care; Urban and Rural Differences; Ekiti State; Primary Health Centers (PHCs)

\section{INTRODUCTION}

Focused antenatal care (FANC) became the recommended type of antenatal care following the publication of a WHO trial on antenatal care where it was discovered that more frequent visits (of the traditional antenatal care approach) do not necessarily improve pregnancy outcomes and advocate a minimum of 4 visits for pregnancies without complications scheduled as First visit: within 16 weeks or when woman first thinks she is pregnant, Second visit: At 20 - 24 weeks or at least once in second trimester, Third visit: At 28 - 32 weeks and Fourth visit: At 36 weeks or later. Limited resources of developing countries like Nigeria can be redirected to give better quality antenatal care services across the recommended four visits [1].

Every year, about 52,900 women die from pregnancy related complication and maternal mortality ratio in Nigeria is 545 per 100,000 live births. [2]. One in 13 Nigerian women stands a chance of experiencing maternal death. Neonatal mortality is equally high in Nigeria it is about 48 per 1000 live births. However, most of these mortalities are of preventable and treatable causes [3]. 
Antenatal care is more important in Nigeria as a developing country because of the risks of malaria and anaemia in poorly nourished women, as well as risk of tetanus. Studies on risk factors of maternal mortality have shown that lack of antenatal care increases the risk of maternal mortality [4]. Focused antenatal care acknowledges that every pregnant woman is at risk for complications, and therefore advocates that all pregnant women should receive the same basic care and monitoring for complications [5].

With regards to antenatal care, age, level of education and place of residence of the pregnant women have been found to consistently determine utilisation of the service [6]. Inequity exists in the quality of antenatal services available to rural and urban residents, rural residents, poor and less educated women may not benefit from antenatal services or may drop out due to access barriers and low quality services [6]. The presence of more quailfied medical practitioners in urban areas, and the interference of different types of traditional antenatal care with the available maternity care in the rural areas among other factors are responsible for the broad disparities in the practice of focused approach to antenatal care [7].

This study was an attempt to ascertain that the focused approach to antenatal care was being practiced in accordance with the Federal Ministry of Health's guideline (stated in the Malaria Control and Reproductive Health adopted strategy) at the most basic level-Primary Health Centres (PHCs) in both urban and rural areas and to determine the facilitating factors and challenges to the practice of focused antenatal care in urban and rural areas. The findings revealed areas where improvement is needed to improve the practice of focused antenatal care in the PHCs.

\section{METHODS}

The study design was cross-sectional and both qualitative (in-depth interview) and quantitative data collection methods were used to collect data. Of the 18 and 12 PHCs offering maternity services in urban and rural areas respectively, 18 PHCs were selected using simple random sampling (two PHCs were randomly picked each from the four and five local government areas in rural and urban areas respectively). Free health service in the PHCs was in place at the time of this study, a minimum sample size of 173 (for each group) was determined using formula for two independent groups. Proportional allocation was used to determine the number of pregnant women selected in the PHCs. Ethical approval and permission were obtained from Ekiti State Ministry of Health. All the heads of the selected PHCs used were briefed and their informed consents were obtained before the field work commenced. Study population included pregnant women visiting the antenatal clinics in PHCs for at least the first time. Exclusion criterion included pregnant women referred from rural area to urban area or vice versa to eliminate recall bias. Exit interview was conducted in Yoruba language (the local language of the study area) to ensure comprehensibility. Antenatal care exit interview questionnaire of the Safe Motherhood Needs Assessment package was adapted and used to obtain information on services received by the pregnant women and their responses were validated with their maternity cards. Minimum focused antenatal care contents was computed using whether the women received these services: blood pressure check, abdominal examination, fetal heart beat check, proteinuria (urine test), hemoglobin test (blood test), HIV test, Syphilis test as well as whether they had ever received iron drugs, Tetanus toxoid (TT) vaccines, Intermittent Preventive Treatment in pregnancy (IPTp), Long Lasting Insecticide Nets (LLIN), multivitamins and whether the women were directly observed (DOT) when taking the IPTp (sp). The range of health education topics computed in this study included: diet and nutrition, knowledge about EDD and fetal growth, birth-preparedness, complication readiness, danger signs in pregnancy and post partum, HIV screening and prevention of HIV and STIs

Heads of facilities were asked about what they considered as facilitating factors and challenges to the practice and sustainability of focused antenatal care.

\section{ANALYSIS}

Data entry and analysis were done using SPSS version 15-software. Univariate analysis was used to determine the frequencies and proportions of the general characteristics of the study population, bivariate analysis-ChiSquare, was used to show the relationship between the covariates and the dependent variables. Multivariate analysis-logistic regression was used to determine significant predictors of the outcome variables. Level of significance was set at $5 \%$. Content analysis using thematic approach was used to explore the in-depth interview.

\section{RESULT}

The mean age of all the respondents was $27.5 \pm 5.7$ (27.2 \pm 5.5 in urban and $27.8 \pm 5.9$ in rural). In the rural areas, slightly more respondents 119 (59.0\%) belonged to the age group 20 - 29 years compared to 112 (56.0\%) of the urban residents belonging to the same age group, for the age group 30 - 39 years, fewer proportion 64 (32.0\%) were from the rural areas compared to $70(35.0 \%)$ that were from urban areas. More respondents in the rural areas $9(4.5 \%)$ were aged 40 and above compared to the urban areas $1(0.5 \%)$ : the differences in the distribution of age groups between rural and urban areas was found to be significant with $\mathrm{p}<0.01$ (Table 1). There were 
fewer pregnant women who were not working in rural areas $26(13.0 \%)$ than urban areas 63 (31.0\%), more re- spondents 111 (55.5\%) in the rural areas were skilled workers compared to urban respondents 94 (47\%), 63

Table 1. Socio demographic and pregnancy related characteristics of women visiting the antenatal clinics by PHC location.

\begin{tabular}{|c|c|c|c|c|c|c|}
\hline Variable & Rural n (\%) & Urban n (\%) & Total n (\%) & $\chi^{2}$ & df & p-value \\
\hline \multicolumn{7}{|l|}{ Occupation } \\
\hline Not working & $26(13.0)$ & 63 (31.5) & $89(22.2)$ & \multirow[t]{3}{*}{20.6} & \multirow[t]{3}{*}{2} & \multirow[t]{3}{*}{0.000} \\
\hline Skilled & 111 (55.5) & $94(47.0)$ & 205 (51.2) & & & \\
\hline Unskilled & 63 (31.5) & 43 (21.5) & $106(26.5)$ & & & \\
\hline \multicolumn{7}{|l|}{ Parity } \\
\hline None & $59(29.5)$ & 59 (29.5) & 118 (29.5) & \multirow[t]{3}{*}{18.0} & \multirow[t]{3}{*}{2} & \multirow[t]{3}{*}{0.000} \\
\hline Between 1 - 4 & $128(64)$ & $100(50)$ & $228(57.0)$ & & & \\
\hline Above 4 & $13(6.5)$ & $41(20.5)$ & 54 (13.5) & & & \\
\hline \multicolumn{7}{|l|}{ Age } \\
\hline $15-19$ & $8(4.0)$ & $17(8.5)$ & $25(6.2)$ & \multirow[t]{4}{*}{10.1} & \multirow[t]{4}{*}{3} & \multirow[t]{4}{*}{0.018} \\
\hline $20-29$ & 119 (59.5) & $112(56.0)$ & 231 (57.8) & & & \\
\hline $30-39$ & $64(32.0)$ & $70(35.0)$ & 134 (33.5) & & & \\
\hline $40+$ & $9(4.5)$ & $1(0.5)$ & $10(2.5)$ & & & \\
\hline \multicolumn{7}{|l|}{ Marital status } \\
\hline Married & 183 (91.5) & $196(98.0)$ & 379 (94.8) & \multirow[t]{2}{*}{8.5} & \multirow[t]{2}{*}{3} & \multirow[t]{2}{*}{0.004} \\
\hline Single & $17(8.5)$ & $4(2.0)$ & $21(5.2)$ & & & \\
\hline \multicolumn{7}{|c|}{ Gestational age at first ANC visit } \\
\hline $\begin{array}{l}\text { First trimester } \\
\text { Second trimester }\end{array}$ & $\begin{array}{l}72(39.3) \\
95(51.9)\end{array}$ & $\begin{array}{l}90(50.5) \\
76(42.2)\end{array}$ & $\begin{array}{l}162(44.6) \\
171(47.1)\end{array}$ & \multirow[t]{2}{*}{4.2} & \multirow[t]{2}{*}{2} & \multirow[t]{2}{*}{0.121} \\
\hline Third trimester & $16(8.7)$ & $14(7.8)$ & $30(8.3)$ & & & \\
\hline \multicolumn{7}{|c|}{$\begin{array}{l}\text { Means of transportation to the } \\
\text { health facility }\end{array}$} \\
\hline Walked & $132(66.7)$ & 99 (49.5) & $231(58.0)$ & 12.0 & 2 & 0.002 \\
\hline Commercial means & $40(20.2)$ & $61(30.5)$ & $101(25.4)$ & & & \\
\hline Private means & $26(13.1)$ & $40(20.0)$ & $66(16.6)$ & & & \\
\hline \multicolumn{7}{|l|}{ Level of Education } \\
\hline None & $21(10.51)$ & 27 (13.5) & $48(12.0)$ & 5.8 & 3 & 0.125 \\
\hline Primary & $32(16.0)$ & 39 (19.5) & $71(17.8)$ & & & \\
\hline Secondary & $86(43.0)$ & $63(31.5)$ & $149(37.2)$ & & & \\
\hline Tertiary & $61(30.5)$ & $71(35.5)$ & $132(33.0)$ & & & \\
\hline \multicolumn{7}{|c|}{ Other sources of Antenatal care } \\
\hline None & $133(66.5)$ & $114(57.0)$ & 247 (61.8) & 16.2 & 4 & 0.003 \\
\hline Traditional care givers & $12(6.0)$ & $26(13.0)$ & $38(9.5)$ & & & \\
\hline Mission houses & $36(18.0)$ & $32(16.0)$ & $68(17.0)$ & & & \\
\hline Private hospitals & $2(1.0)$ & $14(7.0)$ & $16(4.0)$ & & & \\
\hline SHC/THC & $17(8.5)$ & $14(7.0)$ & $31(7.8)$ & & & \\
\hline \multicolumn{7}{|l|}{ Religion } \\
\hline Christianity & 158 (79\%) & $160(80 \%)$ & 318 (79.5) & 2.7 & 2 & 0.255 \\
\hline Islam & 37 (18.5\%) & 39 (19.5\%) & 76 (19.0) & & & \\
\hline Traditional & $5(2.5 \%)$ & $1(0.5)$ & $6(1.5)$ & & & \\
\hline
\end{tabular}


(31.5\%) of the respondents in the rural areas were unskilled workers compared with 43 (21.5\%) of the urban areas, $(\mathrm{p}<0.01)$. Teenage respondents between ages 15 19 years were fewer in the rural areas $8(4.0 \%)$ than in the urban areas 17 (8.5\%).

There were fewer respondents with no education at all in the rural areas 21 (10.5\%) compared with 27 (13.5\%) of the urban areas; respondents whose highest level of educational attainment was primary education were slightly fewer in rural area $32(16.0 \%)$ than in urban areas 39 (19.5\%), those with secondary education as the highest level of educational attainment were more in rural areas 86 (43.0\%) compared with urban areas 63 (31.5\%); respondents with tertiary education as their highest level of education attained were fewer in rural areas 61 (30.5\%) compared to urban areas 71 (35.5\%) (p $=0.13$ ). With regards to marital status: there were fewer married respondents in the rural areas $183(91.5 \%)$ than in the urban areas 196 (98.0\%), 17 (8.5\%) of the single respondents were rural residents compared to 4 (2.0\%) which were urban residents $(p=0.004)$. There were slightly fewer Christian respondents in rural areas 158 (79.0\%) than urban areas $160(80.0 \%)$, there were slightly fewer Muslim respondents 37 (18.5\%) in rural than in urban areas 39 (19.5\%), however, there were more respondents belonging to the traditional religion in rural areas $5(2.5 \%)$ than urban areas $1(0.5 \%)(\mathrm{p}=0.26)$ (Table 1).

With regards to the pregnancy related variables, respondents with no children were exactly the same proportion 59 (29.5\%) in rural and urban areas respectively. More respondents in rural areas 128 (64.0\%) had less than 4 children compared with those of the urban areas 100 (50.0\%), however, women with more than 4 children were fewer in rural areas 13 (6.5\%), than urban areas 41 (20.5\%); the observed difference was significant $(\mathrm{p}<$ 0.01 ). Of the total number of respondents in the first trimester of their pregnancies, $22(11.2 \%)$ were rural respondents and 13 (6.6\%) were urban residents, a higher proportion $102(51.8 \%)$ of the rural residents were in their second trimester compared to their urban counterparts 97 (49.2\%), fewer respondents 73 (37.1\%) in the rural areas were in the third trimester of their pregnancies compared to $87(44.2 \%)$ those in the urban areas, $(\mathrm{p}=$ 0.11). Regarding transportation to the PHCs; a higher proportion $132(66.7 \%)$ of those that trekked to their PHCs were rural residents compared to urban 99 (49.5\%), fewer respondents went to the PHCs with commercial means in rural areas $40(20.2 \%)$, than urban areas 61 (30.5\%) and also, fewer respondents in the rural areas 26 (13.1\%) came with private means than the urban respondents $40(20.0 \%)(p=0.002)$ (Table 1).

A statistically significant rural-urban difference existed in whether or not the respondents got antenatal care from other places apart from their PHCs in their present pregnancies. More rural respondents 133 (66.5\%) did not register in other places apart from the PHCs compared to $114(57.0 \%)$ of the urban respondents; fewer rural respondents received care from traditional care givers 12 (6.0\%) compared to 26 (13.0\%) urban respondents, more women $36(18.0 \%)$ got care from faith homes in rural areas than in urban areas $32(16.0 \%)$, only two (1.0\%) of the rural respondents got care from private hospital compared to $14(7.0 \%)$ of urban respondents who got care from private hospitals and more rural respondents $17(8.5 \%)$ got care from either secondary or tertiary health centres compared to 14 (7.0\%) of the urban respondents $(\mathrm{p}=0.003)$ (Table 1).

Table 2 shows the rural-urban differences in the variables used for computing the minimum content of focused antenatal care.

A lower proportion 41 (20.7\%) of respondents in the rural areas had the minimum contents of FANC compared to urban areas where 58 (29.3\%) of the respondents did the same. $(p=0.05)$. Majority $355(89.6 \%)$ of the respondents were taught a wide range of health education topics however the proportion of respondents taught these topics were slightly lower in the rural areas $177(88.5 \%)$ compared to urban areas $178(90.8 \%)(\mathrm{p}=$ 0.45) (Table 3).

Logistic regression analysis of standard contents of FANC and on location showed that urban respondents were about 1.6 times more likely to receive the minimum contents of FANC than rural respondents. OR $=1.6,95 \%$ $\mathrm{CI}=1.00-2.51$.

With regards to challenges and facilitating factors to FANC in the rural and urban PHCs, the findings on the qualitative part of the study are revealed under the following sub-headings.

\section{FACILITATING FACTORS}

The major facilitating factor to antenatal care is the free health service scheme in place in Ekiti state. Respondents compared the rate of antenatal bookings before the free health service with the present situation; the respondents in the urban areas believed that they had seen between $50 \%$ and $100 \%$ percent increase in the patronage while those in the rural areas opined that the increase was normal; just by about 10 percent.

“... before the free health service, many people use to go to the TBAs \{Traditional Birth Attendants\}, this time around they now come here because everything is free, We have hundred percent increase now compared to when the service was not free" (Chief matron Urban PHC 1).

“... we have a free health service now, the pregnant 
Table 2. Percentage distribution of variables used to form minimum contents of focused antenatal care received between rural and urban women.

\begin{tabular}{|c|c|c|c|c|c|c|}
\hline Variable & Rural n (\%) & Urban n (\%) & Total n(\%) & $\chi^{2}$ & df & p-value \\
\hline \multicolumn{7}{|c|}{ Blood pressure } \\
\hline Yes & $200(100)$ & $196(98.0)$ & $396(99.0)$ & \multirow{2}{*}{4.040} & \multirow{2}{*}{1} & $0.123^{*}$ \\
\hline No & $0(0)$ & $4(2.0)$ & $4.0(1.0)$ & & & \\
\hline \multicolumn{7}{|c|}{ Abdominal examinations } \\
\hline Yes & 195 (97.5) & $200(100)$ & 395 (98.8) & & & \\
\hline No & $5(2.5)$ & $0(0)$ & $5(1.2)$ & 5.063 & 1 & $0.061^{*}$ \\
\hline \multicolumn{7}{|c|}{ Fetal heart beat } \\
\hline Yes & 199 (99.5) & 199 (99.5) & 398 (99.5) & \multirow{2}{*}{0.000} & \multirow{2}{*}{1} & \multirow{2}{*}{$1.000^{*}$} \\
\hline No & $1(0.5)$ & $1(0.5)$ & $2(0.5)$ & & & \\
\hline \multicolumn{7}{|c|}{ Blood test (Hb) } \\
\hline Yes & 191 (95.5) & 177 (88.9) & $368(92.2)$ & \multirow{2}{*}{5.982} & \multirow{2}{*}{1} & \multirow{2}{*}{0.014} \\
\hline No & $9(4.5)$ & $22(11.1)$ & $31(7.8)$ & & & \\
\hline \multicolumn{7}{|l|}{ Urinalysis } \\
\hline Yes & 192 (96.0) & $168(84.0)$ & $360(90.0)$ & \multirow{2}{*}{16.000} & \multirow{2}{*}{1} & \multirow{2}{*}{0.000} \\
\hline No & $8(4.0)$ & $32(16.0)$ & $40(10.0)$ & & & \\
\hline \multicolumn{7}{|l|}{ TT vaccine } \\
\hline Yes & 194 (97.0) & 177 (88.5) & 371 (92.8) & \multirow{2}{*}{10.744} & \multirow{2}{*}{1} & \multirow{2}{*}{0.001} \\
\hline No & $6(3.0)$ & $23(11.5)$ & $29(7.2)$ & & & \\
\hline \multicolumn{7}{|l|}{ IPTp } \\
\hline Yes & $194(97.0)$ & $191(96.0)$ & 385 (96.2) & \multirow{2}{*}{0.307} & \multirow{2}{*}{1} & \multirow{2}{*}{$0.600^{*}$} \\
\hline No & $6(4.0)$ & $8(3.0)$ & $14(3.5)$ & & & \\
\hline \multicolumn{7}{|l|}{ DOT(IPTp) } \\
\hline Yes & $50(25.1)$ & $106(53.0)$ & $255(63.9)$ & \multirow{2}{*}{20.693} & & 0.000 \\
\hline No & & $94(47.0)$ & $144(36.1)$ & & & 0.000 \\
\hline Iron & & & & & & \\
\hline Yes & $200(100)$ & 189 (94.5) & 389 (97.2) & 11311 & 1 & $0001^{*}$ \\
\hline No & $0(0)$ & $11(5.5)$ & $11(2.8)$ & 11.311 & & 0.001 \\
\hline LLINs & & & & & & \\
\hline Yes & $161(80.5)$ & 139 (70.9) & $300(75.0)$ & 4948 & 1 & \\
\hline No & 39 (19.5) & 57 (29.1) & $96(24.0)$ & 4.948 & 1 & 0.026 \\
\hline HIV tests & & & & & & \\
\hline Yes & $108(54.0)$ & $112(56.0)$ & $220(55.0)$ & 0457 & 2 & 0796 \\
\hline No & $90(45.0)$ & 87 (43.5) & $177(44.2)$ & $0.45 /$ & 2 & 0.796 \\
\hline Syphilis test & & & & & & \\
\hline Yes & $62(31.0)$ & $70(35.0)$ & $132(33.0)$ & 1621 & 2 & 0445 \\
\hline No & 135 (67.5) & 129 (64.5) & $264(66.0)$ & 1.621 & 2 & 0.445 \\
\hline Multivitamin & & & & & & \\
\hline Yes & $181(90.5)$ & $128(64.0)$ & $309(77.2)$ & 39959 & 2 & 0000 \\
\hline No & $19(9.5)$ & $72(36)$ & $91(22.8)$ & 39.959 & 2 & 0.000 \\
\hline
\end{tabular}

"Values of Fishers' exact test; Values in bold represent the values significant at $\mathrm{p}<0.005$

women come more than before, the increase is about10 percent, it is not all that much but just increasing little by little” (Matron Rural PHC 1).

Concerning the supply and availability of test kits and malaria prevention materials, respondents from urban health facilities responded that the tests kits and other materials needed are supplied by the government and they were always available, however, two of the four rural health facilities respondents said that the HIV tests kits were not available at the time of this study, but in all the respondents mentioned that the government supplies all they need.

“... HIV test kits are not always available, but it is very much available now, we always have the LLINS and the SP drugs” (Midwife Service Scheme officer Urban PHC 3). 
Table 3. Percentage distribution of minimum contents of focused antenatal care received by rural and urban women.

\begin{tabular}{|c|c|c|c|c|c|c|}
\hline Variable & Rural n (\%) & Urban n (\%) & Total n (\%) & $\chi^{2}$ & df & p-value \\
\hline \multicolumn{7}{|c|}{$\begin{array}{l}\text { Was minimum FANC } \\
\text { Content received? }\end{array}$} \\
\hline Yes & 41 (20.7) & 58 (29.3) & $99(25.0)$ & 3.892 & 1 & 0.05 \\
\hline No & 157 (79.3) & $140(70.7)$ & $297(75.0)$ & & & \\
\hline \multicolumn{7}{|c|}{$\begin{array}{l}\text { Were the women } \\
\text { taught the range of topics? }\end{array}$} \\
\hline Yes & 177 (88.5) & 178 (90.8) & 355 (89.6) & 0.572 & 1 & 0.45 \\
\hline No & $23(11.5)$ & $18(9.2)$ & 41 (10.4) & & & \\
\hline
\end{tabular}

“... Both the mosquito nets and the intermittent Preventive drugs are provided by the government; we have never run short of them, $\cdots$ the government is trying, they supply us with all the kits” (Matron Rural PHC 4).

\section{CONCERNS ABOUT THE REDUCED VISITS}

Majority of the respondents felt that their patients appreciated the focused approach to antenatal care especially the aspect of the reduced visits; the respondents thought FANC will give their patients more time to do other things. However, three out of the nine respondents in both urban and rural areas felt that it will take time for the patients to get accustomed to this new model.

“... many of our pregnant mothers are used to the former one, when you give them 2 months or 6 weeks appointment they raise eyebrow and say wow "so I won't come until that time." But all that we used to tell them is that if you have any complaint before then, you are free to come" (Chief Matron Urban PHC 4).

“... it is not practicable here to be sincere because before I came here they used to come weekly and it is not suppose to be like that, but when I came I was trying to correct it but the clients find it difficult to adjust” (Matron Rural PHC 1).

\section{GENERAL CHALLENGES}

In all, the respondents reported having some challenges with the pregnant women. The general complaints in the urban areas included the fact that a lot of the pregnant women still receive care from faith homes and traditional care givers, the pregnant women miss appointments especially if it fell on market days. These are similar to those of the rural areas where the respondents reported that some of their patients had negative attitudes towards ANC which suggested to the health care providers that the pregnant women perceived the antenatal care visits as sheer waste of time. However, some of the respondents gave entirely different complains which included high parity and late ANC registration excerpted below:

“... the devastating challenge with the women is that, we still see Gravida VII, Gravid VI. They are not using family planning well” (Matron Urban PHC 1).

“... they don't come on time to register, they will be at least 36 weeks before they come to register for the first time, even when they register early they don't keep to appointments” (Midwife Service Scheme Officer Rural PHC 3).

\section{DISCUSSION}

Focused antenatal care sometimes referred to as a new model of antenatal care is the adopted antenatal care model in Nigeria; evident in the training and orientation package of the Federal Ministry of Health and malaria action. It was adopted in Tanzania in year 2002, this new model is what is being practiced in Ghana, Malawi and Kenya.

Having established that FANC is the standard type of antenatal care in Nigeria, there is the need to evaluate whether or not the standard is being followed in urban and rural areas. The recommended standard content involves only examinations and tests that serve an immediate purpose and that have been proven to be beneficial; these examinations include measurement of blood pressure, testing of urine for proteinuria, and blood tests to detect syphilis, severe anaemia and HIV [1]. Routine weight and height measurement at each visit is considered optional, suggesting that some of these contents are subject to the country's discretion. The minimum content of FANC in this study was based on thirteen standard beneficial examinations and services and only 25\% of the pregnant women received the standard contents of FANC. One major reason that could explain the low standard of FANC is the one provided some years ago [8] which is that when policies have been adopted, they do not automatically translate into quality services at the 
local level which in this case is at the primary health care level; this means that the standard model of antenatal care in the PHCs is presently experiencing a gradual transition to become the high quality and efficient model it is meant to be.

Not surprisingly, the urban residents were more likely to have received the minimum contents of FANC than their rural counterparts, this finding is supported the report of a study on maternal health services where it was found out that $57.0 \%$ of urban women have access to safe motherhood services compared to $29 \%$ in the rural areas $[1,6]$. It is recommended that pregnant women should be counseled on different topics of education; this aspect was examined in this study using eight topics, and $89.6 \%$ of the respondents were taught the health education topics, however, more respondents in urban areas $90.8 \%$ were taught the topics compared with the rural areas $88.5 \%$, although the difference appears small, but it emphasizes the fact that urban women enjoy better ANC services than rural women [9].

Qualitative aspect of this study looked at the facilitating factors and challenges to the practice of FANC in Ekiti state PHCs; one major facilitating factor is the free health service project in government PHCs in the state. Respondents reported that there has been increase in the patronage of antenatal care than when patients were paying. The respondents also acknowledged the support of the government and non-governmental organizations in ensuring that tests kits, drugs and LLINs were always available.

The reported challenge militating against the practice of focused antenatal care at the PHC level is the fact that the pregnant women delayed adoption of the change to the new model, this is in agreement with the findings of a study where the respondents expressed fears about poor service with regards to the reduced visits [10]; some of the in-depth interview respondents believed FANC is impracticable which could just be a pointer to the fact that the health care providers did not fully comprehend the advantages, goals and purpose of FANC [11].

\section{CONCLUSIONS}

Rural-urban differences were noticed in this study, implying that urban dwellers enjoy better antenatal care than their rural counterparts: in most developing countries, access to safe motherhood services in rural areas is more limited than in urban areas. This issue is of particular significance for Nigeria since the majority (52 percent) of her population lives in rural areas.

The benefits of quality maternal health service especially antenatal care cannot be overemphasized hence efforts should be intensified so that place of residence will not necessarily dictate whether high or low quality health care especially antenatal care will be received. Standard antenatal care should be received by all pregnant women regardless of their locations. PHCs are the first level of health care, closest to the people; they should be brought to standard, improved to bring better efficiency in the delivery of health care services especially antenatal care, besides, generalized standard contents of antenatal care may be made available in hospitals and public places so that the recipients of this service will not settle for less.

\section{REFERENCES}

[1] Villar, J., Ba’aqeel, H., Piaggio, G., Lumbiganon, P., Miguel, B.J. and Farnot, U. (2001) WHO antenatal care randomised trial for the evaluation of a new model of routine antenatal care. The Lancets, 357, 1551-1564. doi:10.1016/S0140-6736(00)04722-X

[2] National Population Commission (NPC) [Nigeria] and ICF Macro (2009) Nigeria demographic and health survey 2008. National Population Commission and ICF Macro., Abuja, 125-128.

[3] FMOH and NPHCDA (2012) Midwives Service Scheme Manual. Harmonised concept 2009. www.prrinmnch.org/.../NCHMEMOonbringingPHCUOR draft2011

[4] AbouZahr, C. and Wardlaw, T.M. (2001); Maternal mortality at the end decade: What sign of progress? Bulletin of the World Health Organization, 79, 561-573.

[5] World Health Organisation/United Nations International Children's Fund (2003) Antenatal care in developing countries. Promises, achievements and missed opportunities-An analysis of trends, levels and differentials, 19902001. WHO, Geneva.

[6] Oladapo, O.T., Iyaniwura, C.A. and Sule, A.O. (2008) Quality of antenatal care at primary care level in Southwest Nigeria. African Journal of Reproductive Health, 12, 71-92.

[7] Babalola, S. and Fatusi A. (2009) Determinants of use of maternal health services in Nigeria-Looking beyond individual and household factors. BMC Pregnancy and Childbirth, 9, 43 doi:10.1186/1471-2393-9-43

[8] Zimbabwe HIV Prevention (1999) A tool for maternal health advocates-Maternal and neonatal program effort index. The Maternal Health Study (MNPI), The Futures Group International.

[9] Dairo, M.D. and Owoyokun, K.E. (2010) Factors affecting the utilization of antenatal care services in Ibadan, Nigeria. Benin Journal of Post Graduate Medicine, 12, 3-13.

[10] Aniebue, P.N. and Aniebue, U.N. (2010) Women's perception as a barrier to focused antenatal care in Nigeria: the issue of fewer antenatal visits, Medicine Health Policy and Planning, 26, 423-428. doi:10.1093/heapol/czq073

[11] Amosu, A.M., Degun, A.M., Thomas, A.M., Olanrewaju, 
M.F., Babalola, A.O., Omeonu, P.E., Ola, O.O., Oyerinde, O.O. and Nwogwugwu, S. (2011) A study on the acceptance and practice of focused antenatal care by healthcare providers in the South-West Zone of Nigeria. Archives of Applied Science Research, 3, 484-491. 